\title{
The effects of hormones and morphine on both analgesia and the lordosis response produced by cervical probing in the female rat
}

\author{
ELLEN F. ROSEN \\ College of William and Mary, Williamsburg, Virginia 23185 \\ KATHLEEN C. WESTLAKE \\ Virginia Commonwealth University, Richmond, Virginia 23284 \\ and \\ LINDA C. PETTY \\ Hampton Institute, Hampton, Virginia 23668
}

\begin{abstract}
Two experiments were conducted to assess the effects of sex hormones and morphine on the lordosis response and the analgesia produced by cervical probing in the female rat. Estrogen and progesterone were found not to affect responses to standard tests of nonciception (tail flick and tail pressure), but estrogen did increase the lordosis response. Cervical probing and morphine were both found to produce significant analgesia, but hormones did not alter the effectiveness of either. Thus, the pain-blocking mechanism involved is apparently not hormonedependent.
\end{abstract}

Several behavioral studies indicate that vaginal stimulation during mating may be aversive (Bermant \& Westbrook, 1966; Hardy \& DeBold, 1972; Pierce $\&$ Nuttall, 1961) in the rat. Analgesia induced by vaginal stimulation in the female rat has been reported by many researchers (Komisaruk \& Larsson, 1971; Rosen, Petty, \& Westlake, Note 1). The analgesia produced by stimulation, such as intromission by the male in the natural copulatory situation, may make tolerable the repeated intromissions that are necessary for successful impregnation (Adler, 1969). Komisaruk (1971) has shown that the magnitude of the lordosis response to cervical probing is estrogen-dependent. If the magnitude of this response is related to "sexual readiness," then pain inhibition ought also to be estrogen-dependent. If this relationship were supported, it would provide a possible explanation of the female's sexual rejection (biting, kicking) of the male when not in estrus. In nonestrus states, the painful component of mating is not inhibited and thus escape or avoidance behavior is elicited; in the estrus state, the painful component is blocked and approach behavior is elicited.

\section{EXPERIMENT 1}

\section{Method}

Subjects. Forty-five female Holtzman albino rats (about 100 days old) were used as subjects. The animals were all bilaterally ovariectomized approximately 5 weeks before the beginning of the test trials. The animals were housed in individual cages under a 12-h light, 12-h dark schedule at about $26^{\circ} \mathrm{C}$.

Apparatus. The tail-flick apparatus was modeled after that of Akil and Mayer (1972). The tip of the rat's tail was placed over a hole cut in a metal box. The bulb (projection lamp, General Electric, BHD) was turned on; it was programmed to turn off after $7 \mathrm{sec}$, but the rat could flick its tail at any time. The latency of the flick was measured with a stopwatch. The animal was held in a restraining device mounted at the same level as the light aperture so that the animal's tail remained level. Room temperature ranged from $27^{\circ}$ to $29^{\circ} \mathrm{C}$. The temperature at the aperture reached about $54^{\circ} \mathrm{C}$ by the end of the $7-\mathrm{sec}$ period with a $1.5-\mathrm{min}$ intertrial interval.

The tail-pinch apparatus consisted of a push-pull, spring scale (Chalston, New York) mounted in a wooden frame. It was attached to a $32.2-\mathrm{mm}^{2}$ brass plate. The animal's tail was inserted in a wooden channel such that the most distal end of the tail (but not the very tip) was inserted between a stationary brass plate and the plate mounted on the scale. The scale was then pushed, pinching the tail. The scale was pushed until either the animal vocalized or contracted its body in the holder. The pressure applied was never allowed to exceed $1.81 \mathrm{~kg}$ to insure that the animal's tail not be damaged.

Procedure. After surgery, the subjects were randomly assigned within blocks of 15 animals to one of five hormone treatment combinations, estrogen and progesterone, estrogen and oil, oil and progesterone, oil and oil, and oil and androgen. The hormones used were estradiol benzoate (EB) $(1 \mu \mathrm{g} / 100 \mathrm{~g}$ body weight), progesterone (P) $(0.5 \mathrm{mg})$, and testosterone propionate (TP) $(0.1 \mathrm{mg} / 100 \mathrm{~g}$ body weight). All were given subcutaneously and were dissolved in sesame seed oil (EB and TP given $0.05 \mathrm{cc} / 100 \mathrm{~g}$ body weight and $\mathrm{P} 0.2 \mathrm{cc}$ ). EB injections were given 44 to $46 \mathrm{~h}$ prior to testing, $P$ and TP were injected 4 to $6 \mathrm{~h}$ prior to testing. The group receiving androgen (TP) may be viewed as a control: a hormone injected but with time course too short probably to be effective (Meyerson, Lindström, Nordström, \& Ågmo, 1973). 
The animals were allowed 2 weeks to recover from surgery. The next week, the first 15 animals were given training trials for 5 consecutive days on the tail-flick apparatus ( 4 trials/day) and the tail-pressure apparatus ( 1 trial/day). The training procedure was as follows: the animal was inserted in the wire restraining device and the tail was placed across the tail-flick apparatus. If the animal moved the tail before the light was turned on, the trial was aborted and a new trial was begun. A 1.5 -min rest period was allowed between trials. The tail-pressure trial was similar. The next week, the second 15 were trained, and the following week, the remaining 15 . The week after that, the animals were injected according to the hormone treatment combination to which they had been assigned, and then all were tested on the same day.

The testing consisted (in the order of presentation) of vaginal smears, cervical probing, four tail-flick trials, one tail-pressure trial, four tail-flick trials while cervical probing was performed, and one tail-pressure trial with cervical probing, followed by one tail-flick trial with cervical probing (7-sec in duration) with the probe being removed when the light was turned on. All of these procedures were the same as during training, except that during probing trials the animal was restrained by hand. The vaginal smear was made using a water-moistened cotton swab and a microscope slide. The smear was rated as a very strong estrus smear, a strong estrus smear, a moderate estrus smear, a mildly nonestrus smear, or completely nonestrus smear. Then cervical probing was performed. This was done using the procedure of Rosen and Petty (1974). A glass 1-cc water-moistened syringe plunger is placed in the vagina and slowly pressed against the cervix. The perineum is palpated and a Polaroid photograph (with room illumination only) is made of the posture of the rat. Later, the response is evaluated by measuring the photographic dimensions of the distance of the nose and rump above the baseline established by the front and back paws. These two numbers are then added together, and the height of the lowest point on the back is then subtracted twice to give the lordosis response. All photographs are made at the same settings and position of the camera so that these measurements are directly comparable. Cervical probing during the tail-flick and tail-pressure trials was done in the same fashion, but no photographs were made.

\section{Results}

The vaginal smears were analyzed by a one-way analysis of variance. The smears were rated on a 1to-5-point scale as to presence of cornified material. The $F$ for the treatment effect was significant, $F(4,40)$ $=2.97, \mathrm{p}<.05$. The average smear ratings are presented in the first column of Table 1 .

A summary of the data collected on the other test measures is presented in the remaining columns of Table 1. The measures were analyzed by one-way analyses of variance. The injection combinations did significantly affect the lordosis response, $F(4,40)$ $=2.70, \mathrm{p}<.05$. Comparisons showed that only the androgen group differed significantly, Tukey's $q(5,40)=7.12, p<.05$. Inspection of the group means suggests that there was no relation between average smear rating and average lordosis response, $\mathrm{r}(4)=.27, \mathrm{p}>.5$. However, these results may occur because of the significant difference in variability of the lordosis response among the groups, Fmax $(5,8)=17.3, p<.01$. None of the other measures show such great variability.

Hormones did not have a significant effect on any of the pain responses, as measured between groups. When the pain tests were repeated in combination with cervical probing, there was a dramatic increase in tail-flick latencies and tail-pressure thresholds. Because upper limits were used to prevent damage to the subjects, the averages reported minimize the effects of cervical probing. Thus, analyses of variance are inappropriate. However, cervical probing with palpation almost completely blocked the tailflick response. Of the $\mathbf{4 5}$ animals on the four trials, there were only 13 instances in which a tail flick occurred (a 7\% flick rate). On the test trials without cervical probing, there were only two trials without flicks out of the total 180 trials (99\% flick rate). A similar result occurs in the tail-pressure test. Of the 45 animals only one animal failed to show signs of distress before the upper limit of pressure allowed without cervical probing (98\% response). However, when cervical probing was added, only 10 animals responded (20\% response). Again, cervical probing with palpation inhibited the distress response to tail pressure.

On the aftereffects trial, there was no significant effect of the hormone treatments. Over all animals in the five groups, the average latency to flick increased from an average of 2.49 -sec on the nonprobed test trials to $4.06-\mathrm{sec}$ on the aftereffects trial, $t(44)=$ $5.56, \mathrm{p}<.001$.

Table 1

Summary Statistics for Experiment 1

\begin{tabular}{|c|c|c|c|c|c|c|c|c|c|c|c|c|c|}
\hline \multirow[b]{3}{*}{ Hormone Treatment } & \multirow{3}{*}{$\begin{array}{l}\text { Average } \\
\text { Smear } \\
\text { Rating }\end{array}$} & \multirow{2}{*}{\multicolumn{2}{|c|}{$\begin{array}{l}\text { Lordosis } \\
\text { Response } \\
\text { (mm) }\end{array}$}} & \multicolumn{4}{|c|}{ Tail Flick Latency (sec) } & \multicolumn{4}{|c|}{ Tail Pressure (kg) } & \multirow{2}{*}{\multicolumn{2}{|c|}{$\frac{\text { Tail Flick (sec) }}{\text { Aftereffect }}$}} \\
\hline & & & & \multicolumn{2}{|c|}{$\begin{array}{l}\text { Without } \\
\text { Probe }\end{array}$} & \multicolumn{2}{|c|}{$\begin{array}{l}\text { With } \\
\text { Probe }\end{array}$} & \multicolumn{2}{|c|}{$\begin{array}{l}\text { Without } \\
\text { Probe }\end{array}$} & \multicolumn{2}{|c|}{$\begin{array}{l}\text { With } \\
\text { Probe }\end{array}$} & & \\
\hline & & Mean & SD & Mean & SD & Mean & SD & Mean & SD & Mean & SD & Mean & SD \\
\hline Estrogen-Progesterone & 3.2 & 8.22 & 3.07 & 2.66 & .45 & 7.00 & .00 & .99 & .20 & 1.66 & .28 & 4.61 & 2.05 \\
\hline Estrogen-Oil & 2.9 & 8.00 & 2.65 & 2.47 & .54 & 7.00 & .00 & 1.03 & .18 & 1.68 & .27 & 2.86 & .73 \\
\hline Oil-Progesterone & 1.8 & 8.56 & 2.30 & 2.57 & .67 & 6.93 & .20 & .88 & .25 & 1.78 & .12 & 4.19 & 1.72 \\
\hline Oil-Oil & 1.9 & 4.30 & 6.87 & 2.40 & .35 & 6.86 & .43 & 1.23 & .28 & 1.81 & .03 & 4.19 & 1.96 \\
\hline Oil-Androgen & 2.4 & 1.44 & 9.64 & 2.37 & .25 & 7.00 & .00 & .94 & .46 & 1.78 & .12 & 4.46 & 1.78 \\
\hline
\end{tabular}

Note $-N=9$ in all treatment conditions. 


\section{EXPERIMENT 2}

Meyerson (1964a, 1964b, 1964c) and Zemlan, Ward, Crowley, and Margules (1973) have suggested that the stereotypic sexual response (lordosis) in the female rat is under the inhibitory control of serotonin and that progesterone functions to release this system by acting as an antagonist of serotonin. The analgesic effects both of morphine (Tenen, 1968; Way \& Shen, 1971) and direct electrical stimulation of the central gray (Akil \& Mayer, 1972) have been shown to be serotonin-dependent. If progesterone is a serotonin antagonist, then it ought to reduce the analgesic effect of morphine.

Further, folklore and sex education books (e.g., Katchadourian \& Lunde, 1972) have suggested that sexual arousal is enhanced by some nociceptive stimuli. If nociceptive stimulation does, in fact, facilitate sexual arousal, then morphine should decrease the lordosis response in the primed female in that it would block sensation and therefore painful stimulation caused by cervical probing. Vaginal stimulation triggers the lordosis response and the analgesia associated with it. If morphine blocks the transmission of this stimulation, then a reduction in the lordosis response would be expected.

A procedural change was made in this experiment. Instead of using cervical probing plus palpation on the pain tests, only cervical probing was used. This was done in an attempt to eliminate the ceiling effect which occurred in Experiment 1 so that if morphine were to further enhance the analgesia produced by cervical probing, it would be apparent.

\section{Method \\ Subjects. The same 45 female Holtzman rats were used as in}

Experiment 1. They were approximately 200 days of age at the beginning of the study. The animals were housed in 12-h light, 12 -h dark conditions in individual cages at about $26^{\circ} \mathrm{C}$.

Procedure. The apparatus and procedure used were the same as in Experiment 1. All animals were randomly assigned to one of six injection treatments: estradiol benzoate $(0.1 \mathrm{mg} / .05 \mathrm{cc}$ sesame oil; $.05 \mathrm{cc} / 100 \mathrm{~g}$ body weight), given subcutaneously, or sesame seed oil $46 \mathrm{~h}$ prior to testing; progesterone $(.5 \mathrm{mg} / .1 \mathrm{cc}$ oil, .1 cc/rat) given subcutaneously, or sesame seed oil or testosterone propionate $(.1 \mathrm{mg} / .05 \mathrm{cc}$ sesame seed oil, $.05 \mathrm{cc} / 100 \mathrm{~g}$ body weight), given subcutaneously $5 \mathrm{~h}$ prior to testing; and finally, morphine sulfate $(10 \mathrm{mg} / \mathrm{ml}$ physiological saline; $.05 \mathrm{cc} /$ $100 \mathrm{~g}$ body weight), given intraperitoneally, or physiological saline $50 \mathrm{~min}$ prior to testing. There were a total of six groups: an estrogen-progesterone-morphine group $(\mathrm{N}=10)$, an estrogenprogesterone-saline group $(\mathrm{N}=9)$, an estrogen-oil-morphine group $(\mathrm{N}=8)$, an estrogen-oil-saline group $(\mathrm{N}=9)$, an oilandrogen-morphine group $(\mathrm{N}=5)$, and an oil-androgen-saline group $(\mathrm{N}=4)$. These last two groups can be viewed as additional controls: they received a hormone which probably does not have an effect because the time course is too short (Meyerson, Lindström, Nordström, \& Ågmo, 1973).

The lordosis response to cervical probing was used first following the procedure of Rosen and Petty (1974). Then the tail-flick and tail-pressure procedures were given as in Experiment 1, but without palpation. Then the tail-flick and tail-pressure procedure was repeated with cervical probing but without palpation of the perineum. Finally, one tail-flick trial was given to assess the aftereffects of cervical probing. On this trial, cervical probing was continued for $30 \mathrm{sec}$, the rod was removed, and the tail-flick trial proceeded immediately.

\section{Results}

The findings of this experiment are summarized in Table 2. Strength of association was measured using the $r_{m}$ statistic (Friedman, 1968). The lordosis response data were analyzed as a hormone combination (progesterone, oil, or androgen) by drug (morphine or saline) independent group unweighted means analysis of variance. There was a significant effect of morphine, $\mathrm{F}(1,39)=5.53, \mathrm{p}<.05, \mathrm{r}_{\mathrm{m}}>.35$,

Table 2

Summary Statistics for Experiment 2

\begin{tabular}{|c|c|c|c|c|c|c|c|c|c|c|c|c|c|}
\hline \multirow[b]{3}{*}{ Drug } & \multirow{3}{*}{$\begin{array}{c}\text { Average } \\
\text { Smear } \\
\text { Rating } \\
\end{array}$} & \multirow{2}{*}{\multicolumn{2}{|c|}{$\begin{array}{l}\text { Lordosis } \\
\text { Response } \\
\text { (mm) }\end{array}$}} & \multicolumn{4}{|c|}{ Tail Flick Latency (sec) } & \multicolumn{4}{|c|}{ Tail Pressure (kg) } & \multirow{2}{*}{\multicolumn{2}{|c|}{$\frac{\text { Tail Flick (sec) }}{\text { Aftereffect }}$}} \\
\hline & & & & \multicolumn{2}{|c|}{$\begin{array}{l}\text { Without } \\
\text { Probe }\end{array}$} & \multicolumn{2}{|c|}{$\begin{array}{l}\text { With } \\
\text { Probe }\end{array}$} & \multicolumn{2}{|c|}{$\begin{array}{l}\text { Without } \\
\text { Probe }\end{array}$} & \multicolumn{2}{|c|}{$\begin{array}{l}\text { With } \\
\text { Probe }\end{array}$} & & \\
\hline & & Mean & SD & Mean & SD & Mean & SD & Mean & SD & Mean & SD & Mean & SD \\
\hline \multicolumn{14}{|c|}{ Estrogen-Progesterone } \\
\hline $\begin{array}{l}\text { morphine } \\
(\mathrm{N}=10)\end{array}$ & 2.7 & 7.90 & 2.92 & 4.42 & 1.90 & 7.00 & .00 & 1.34 & .31 & 1.54 & .45 & 4.53 & 1.93 \\
\hline $\begin{array}{l}\text { saline } \\
(N=9)\end{array}$ & 3.2 & 8.00 & 2.40 & 2.24 & .21 & 5.00 & 2.04 & .94 & .35 & 1.59 & .28 & 2.79 & 1.26 \\
\hline \multicolumn{14}{|c|}{ Estrogen-Oil } \\
\hline $\begin{array}{l}\text { morphine } \\
(\mathrm{N}=8)\end{array}$ & 2.5 & 5.25 & 4.59 & 4.98 & 1.82 & 7.00 & .00 & 1.40 & .41 & 1.76 & .16 & 5.29 & 2.09 \\
\hline $\begin{array}{l}\text { saline } \\
(N=9)\end{array}$ & 3.8 & 8.11 & 2.71 & 2.22 & .29 & 5.81 & 1.90 & .92 & .13 & 1.47 & .46 & 2.21 & 1.47 \\
\hline \multicolumn{14}{|c|}{ Oil-Androgen } \\
\hline $\begin{array}{l}\text { morphine } \\
(\mathrm{N}=5)\end{array}$ & 1.2 & -1.00 & 10.30 & 4.08 & 2.54 & 6.80 & .45 & 1.34 & .34 & 1.56 & .24 & 4.46 & 2.34 \\
\hline $\begin{array}{l}\text { saline } \\
(N=4)\end{array}$ & 2.2 & 6.00 & 2.94 & 2.20 & .36 & 6.52 & .71 & 1.02 & .23 & 1.48 & .41 & 1.60 & .35 \\
\hline
\end{tabular}


and of the hormone combination, $F(2,39)=5.44$, $\mathrm{p}<.01, \mathrm{r}_{\mathrm{m}}>.45$, but the interaction was nonsignificant, $\mathrm{F}(2,39)=2.02, \mathrm{p}<.10, \mathrm{r}_{\mathrm{m}}>.30$. From Table 2 , it is clear that the morphine groups always exhibited a lesser lordosis response than the corresponding saline group. The average lordosis response for the morphine groups was 5.04, whereas for the saline groups it was 7.68. Tukey's tests were used to compare the effect of the hormone. Only the androgen group differed significantly from the estrogen and progesterone combination $\mathrm{q}(3,39)=$ $4.78, p<.05$, and from the estrogen and oil combination, $\mathrm{q}(3,39)=3.81, \mathrm{p}<.05$. Thus, morphine depresses the lordosis response and progesterone has no effect on it. The apparent depressing effect of androgen is misleading; it is the androgen group's lack of estrogen which causes these animals to be so much lower in response to cervical probing.

Using the same rating system as in the first experiment, the vaginal smear data showed the same pattern of results as the lordosis response data. The average smear ratings are presented in Column 1 of Table 2. The independent groups, hormone by drug, unweighted means analysis of variance showed a significant effect of hormone treatment on the vaginal smears, $F(2,39)=3.57, p<.05$. The effect of morphine on the smears almost reached significance, $F(1,39)=4.07, p<.05$. The androgen group, receiving no estrogen, had lower smear ratings, and the morphine animals also usually had lower smear ratings than the corresponding saline animals. The interaction was not significant, $\mathrm{F}<1$.

The tail-flick data in this experiment were analyzed as a three-factor repeated measures design using an unweighted means analysis with repeated measures on the cervical probing factor. This was feasible in this experiment in that the ceiling effect (no flicks in $7 \mathrm{sec}$ ) was considerably lessened by the modified probing procedure (no palpation). The means and standard deviations for the tail-flick latencies are presented in Table 2. As in Experiment 1, hormones had no effect on tail-flick latencies, $F<1$. Both morphine, $F(1,39)$ $=29.09, \mathrm{p}<.01$, and cervical probing without palpation, $F(1,39)=102.48, p<.01$, dramatically increased tail-flick latencies. There were no significant interactions. Disregarding the nonsignificant hormone factor, on the four trials given with no cervical probing, $100 \%$ of the saline animals flicked their tails before the 7 -sec cutoff, while $72.8 \%$ of the morphine animals did. When cervical probing was added, the flick rate dropped to $43.2 \%$ for the saline animals and $7.6 \%$ for the morphine animals.

The tail-pressure results are also presented in Table 2. A similar analysis of variance was performed on these data. Again, hormones had no effect on this response, but morphine and cervical probing both significantly decreased responsiveness to tail pressure in general, $F(1,39)=8.77$ and $\mathrm{F}(1,39)=41.30$, respectively, $\mathrm{p}<.01$. However, there was also a significant interaction between morphine and cervical probing, $\mathrm{F}(1,39)=5.24, \mathrm{p}<.01$. The cause of the significant interaction is that adding cervical probing to the already somewhat analgesic morphine group does not increment the analgesia as much as when cervical probing is applied to a nonanalgesic group. These results differ from those found for the tail flick. Disregarding the nonsignificant hormone treatment, the percent responses (squirming, squealing, or distress vocalization before $1.81 \mathrm{~kg} / 32.2 \mathrm{~mm}^{2}$ of pressure is applied) were $100 \%$ for the saline group and $87 \%$ for the morphine group without probing. The addition of cervical probing decreased these percentages to 54.5 and 39.1 , respectively, for the saline and morphine groups.

On the aftereffects trial, there was no effect of hormones on the latency to respond. Morphine significantly increased the latency to flick, $F(1,39)=$ $22.07, p<.01$. The interaction was nonsignificant. Using difference scores to compare tail-flick latencies without cervical probing with the aftereffects trial, no differences were found, $t(22)=0.65$, and $t(23)$ $=0.44$ for the morphine and saline groups, respectively.

\section{DISCUSSION}

The important general findings of these two studies are: (1) hormones have no effect on response to pain, although they do affect the lordosis response, (2) cervical probing significantly inhibits response to pain, (3) the inhibition of the pain response brought about by cervical probing can outlast the cervical probing under certain circumstances, (4) morphine in a dose large enough to produce significant inhibition of the pain response also significantly depresses the lordosis response to cervical probing.

It has been suggested elsewhere (Petty, 1975) that cervical probing may act by affecting units in the mesencephalic central gray which Mayer (1971) has shown to produce analgesia when electrically stimulated. This same area has been suggested to be implicated in the effect of morphine (Mayer \& Liebeskind, 1974). If cervical probing were acting through the same mechanism as morphine, a significant interaction would be expected: i.e., adding one to the other should not produce as great an increment in pain inhibition as each used alone would suggest. In fact, for the tail-flick data, no such result was obtained. However, the tail-pressure data showed such an interaction. This contrary evidence suggests several possibilities: cervical probing and morphine do not act through the same systems to block pain, or 
perhaps tail-pressure and tail-flick tests are not measuring the same kind of pain systems. Murfin and Mayer (Murfin, Note 2) have found similar differences in tail flick and tail pressure. They attribute these differences to the tail-flick response being a spinal reflex and the tail-pressure response probably requiring supraspinal mediation. Clearly, in the present experiment, this seems reasonable, since the response to tail pressure observed was vocalization and/or whole body movement while that required to tail flick was movement of the tail. The present study does not deal with the issue of where the pain blockage occurs. It seems that the animals were still capable of response, in that when cervical probing was used without palpation they did in fact respond in many instances.

The fact that hormonal priming had no effect either on response to pain or on the effectiveness of morphine is extremely interesting. In a primed animal, cervical probing has no greater effectiveness in blocking pain than in an unprimed animal. Thus, this pain-blocking mechanism is not estrogendependent. Furthermore, progesterone failed to antagonize the effects of morphine, which it ought to as a serotonin antagonist, if morphine is serotonindependent.

Crowley, Jacobs, Volpe, Rodriguez-Sierra, and Komisaruk (1976) found, however, that the analgesia produced by cervical probing in their experiment was enhanced by estrogen. They also found that progesterone antagonized this facilitatory effect of estrogen. The apparent discrepancy between our results and Crowley et al.'s (1976) is probably a result of several methodological differences. First, the response observed by Crowley et al. (1976) was vocalization, whereas in the present studies the responses were a tail flick and a whole body flinch. Second, the timing of the estrogen injections was different. In our studies, the animals always receive a single injection $48 \mathrm{~h}$ prior to testing, whereas in the Crowley et al. (1976) study, the animals received daily injections of estrogen for each of the 3 days preceding testing. As a consequence, their animals certainly had higher blood estrogen levels at the time of testing than did our subjects. Third, the effect of estrogen appeared in the amount of cervical pressure required to produce analgesia, a variable which our study did not investigate. Finally, the nociceptive stimulus differs. Crowley et al. (1976) used tailshock, whereas we used both radiant heat and pressure to the tail. In the present studies the results differed for the two techniques that we employed. This suggests that differences might well occur when response to tailshock was compared to response to either radiant heat or tail pressure. Perhaps the pain blockage produced by cervical probing is differentially effective for different types of nociceptive stimulation. Mor- phine did not seem to alter the effectiveness of cervical probing on tail-flick latencies, but there was a decrease of the effectiveness of the tail-pressure stimulus. Perhaps the tail-flick stimulus was not as intense a painful stimulus as the tail pressure. Such a difference might account for these results.

The aftereffects procedure was used to see if cervical probing had similar properties to those reported by Mayer and Liebeskind (1974) for electrical stimulation of the mesencephalic central gray; in other words, to see if the analgesia produced by cervical probing outlasted the stimulation, as does the analgesia caused by intracranial stimulation. In the first experiment, when cervical probing with palpation was done for $7 \mathrm{sec}$, the pain inhibition did outlast the stimulation. In the second experiment, when cervical probing without palpation was used for $30 \mathrm{sec}$, there was no aftereffect. Komisaruk (Note 3 ) has suggested that some kind of exhaustion phenomenon may occur with prolonged cervical probing. He suggests that $30 \mathrm{sec}$ may be long enough to produce such exhaustion. Thus, length of stimulation may be a critical variable in this aftereffect phenomenon.

\section{REFERENCE NOTES}

1. Rosen, E. F., Petty, L. C., \& Westlake, K. C. Effects of sex hormones and cervical probing on response to nociceptive stimulation. Paper presented at the November 1974 meeting of the Psychonomic Society in Boston.

2. Murfin, R. Personal communication, 1976.

3. Komisaruk, B. Personal communication, March 17, 1976.

\section{REFERENCES}

ADLER, N. Effects of the male's copulatory behavior on successful pregnancy of the female rat. Journal of Comparative and Physiological Psychology, 1969, 69, 613-622.

AKIL, H., \& MAYER, D. J. Antagonism of stimulation-produced analgesia by p-CPA, a serotonin synthesis inhibitor. Brain Research, 1972, 44, 692-697.

Bermant, G., \& Westbrook, W. Peripheral factors in the regulation of sexual contact by female rats. Journal of Comparative and Physiological Psychology, 1966, 61, 244-250.

Crowley, W. R., Jacobs, R., Volpe, J., Rodriguez-Sierra, J. F., \& Komisaruk, B. R. Analgesic effect of vaginal stimulation in rats: Modulation by graded stimulus intensity and hormones. Physiology and Behavior, 1976, 16, 483-488.

Friedman, H. Magnitude of experimental effect and a table for its rapid estimation. Psychological Bulletin, 1968, 70, 245-251.

HARDY, D. F., \& DeBold, J. F. Effects of coital stimulation upon behavior of the female rat. Journal of Comparative and Physiological Psychology, 1972, 78, 400-408.

Katchadourian, H. A., \& Lunde, D. T. Fundamentals of human sexuality. New York: Holt, Rinehart, and Winston, 1972. P. 56.

KomisaRUK, B. R. Induction of lordosis in ovariectomized rats by stimulation of the vaginal cervix: Hormonal and neural interrelationships. In C. H. Sawyer \& R. A. Gorski (Eds.), Brain function: Steroid hormones; UCLA Symposium on Brain and Behavior. Los Angeles: UCLA Press, 1971. Pp. 127-141.

KomisaruK, B. R., \& LARsson, K. Suppression of a spinal and a 
cranial nerve reflex by vaginal or rectal probing in rats. Brain Research, 1971, 35, 49-53.

MAYER. D. J. Analgesia produced by focal brain stimulatin in the rat: An anatomical and behavioral analysis. Unpublished doctoral dissertation, UCLA, 1971.

Mayer, D. J., \& Liebeskind, J. C. Pain reduction by focal electrical stimulation of the brain: An anatomical and behavioral analysis. Brain Research, 1974, 68, 73-93.

Meyerson, B. J. Central nervous monoamines and hormone induced estrus behavior in the spayed rat. Acta Physiologica Scandinavia, 1964, 63 (Suppl. 241), 1-32. (a)

MEYerson, B. J. The effect of neuropharmacological agents on hormone-activated estrus behavior in ovariectomized rats. Archives Internationales de Pharmacodynamie et de Therapie, 1964, 150, 4-33. (b)

MEYERSON, B. J. Estrus behavior in spayed rats after estrogen or progesterone treatment in combination with reserpine or tetrabenzine. Psychopharmacologica, 1964, 6, 210-218. (c)

Meyerson, B. J., Lindström, L., Nordström, E., \& Ӓmo, A. Sexual motivation in the female rat after testosterone treatment. Physiology and Behavior, 1973, 11, 421-428.

PetTy, L. C. Alteration of activity in single units in the mesencephalic central gray produced by cervical probing, noxious stimuli, and their combination in the awake, freely moving rat. Unpublished doctoral dissertation, Virginia Commonwealth University, 1975.

Pierce, J., \& Nuttall, R. Self-paced sexual behavior in the female rat. Journal of Comparative and Physiological Psychology, 1961, 54, 310-313.

Rosen, E. F., \& Petty, L. C. Food deprivation effects on some estrogen-sensitive responses in female rats. Physiology and Behavior, 1974, 12, 767-770.

Tenen, S. S. Antagonism of the analgesic effect of morphine and other drugs by p-chlorophenylalanine, a serotonin depletor. Psychopharmacologia, 1968, 12, 278-285.

WAY, E. L., \& SHEN, F. Catecholamines and t-hydroxytryptamine. In D. H. Clovet (Ed.), Narcotic drugs: Biochemical pharmacology. New York: Plenum, 1971. Pp. 229-253.

Zemlan, F. P., Ward, I. L., Crowley, W. R., \& Margules, D. L. Activation of lordotic responding in female rats by suppression of serotonergic activity. Science, 1973, 179, 1010-1011.

(Received for publication December 20, 1976; revision accepted April 13, 1977.) 